\title{
Entrevista com Marshall McLuhan
}

\section{Tradução de Débora Fleck.}

Esta entrevista com Marshall McLuhan foi originalmente publicada na revista francesa L'Express em fevereiro de 1972. Em dezembro de 2011, ela foi traduzida e publicada em português na Revista ALCEU (vol.12, n.23), periódico de Comunicação da PUC-Rio, disponível em http:// revistaalceu.com.puc-rio.br/media/Artigo1\%20 Entrevista\%20MacLuhan.pdf . Graças à gentil concessão da autorização para republicação por parte da Editora PUC-Rio, este texto pôde ser incluído neste número especial dedicado a McLuhan, motivo pelo qual a comissão editorial da E-Compós agradece especialmente.

Nesta entrevista, concedida a uma revista semanal de notícias, McLuhan estava com 60 anos e se encontrava no auge de sua fama, angariando tanto fiéis seguidores quanto inimigos ferrenhos, à direita e à esquerda. Um documento histórico que, feitas as devidas concessões ao espírito da época, revela ainda hoje o brilho intelectual, a atitude provocativa e as afirmações polêmicas que fizeram a fama do "profeta da era elétrica".
L'Express: 0 senhor sabia que na França o seu nome é muitas vezes tido como sinônimo de capitalismo americano? Marshall McLuhan: Quem diz isso?

L'Express: Os intelectuais de esquerda, por exemplo.

M. McLuhan: Essa equação McLuhan = capitalismo não tem nenhuma utilidade como categoria. Na verdade, o que eles dizem é que a minha forma de olhar o século XX não é a mesma que a deles. Se não estou do lado deles, então sou contra eles. Não tenho nada contra o comunismo, exceto pelo fato de ele ser tremendamente melancólico.

Não há mais classes sociais em nossa sociedade, elas simplesmente não existem mais. Não é possível ter classes sociais com essa velocidade instantânea, uma vez que o sistema de classes supõe que as coisas permaneçam em seus lugares. Agrade ou não, isso é um fato.

Os marxistas são uns tolos. Eles fornecem para um monte de gente uma válvula de segurança no plano emocional, mas sem o mínimo entendimento de nada. 
O que me interessa são as inovações como tais, e sobretudo o efeito dessas inovações. Eu estudo o que aconteceria se fizéssemos tal ou tal coisa. A maior parte das pessoas pensa no que acontece com nossos filhos quando eles assistem a violência na televisão. Já eu não me preocupo nem um pouco com isso. O que estudo é por que os indivíduos têm necessidade de violência, e isso não tem nada a ver com os programas. Analiso os fenômenos partindo dos efeitos em direção à causa, e não começando da causa para chegar aos efeitos, como é o hábito mais comum. É como um playback. Analiso tudo em playback.

\section{L'Express: É o contrário do que estamos} acostumados a fazer. Por que o senhor age dessa forma?

M. McLuhan: Porque quando invertemos a ordem de um processo, é aí que descobrimos sua estrutura, seu esquema. Ao passo que nem o estudo de sua emissão nem de sua recepção fornecem o esquema de uma mensagem ou de uma ação. Isso eu aprendi com a publicidade. No mundo publicitário, não se começa criando o anúncio e sim estudando o efeito que se deseja produzir. Cria-se a causa depois de o efeito ter sido definido. Da mesma forma, quando se quer resolver um problema de gestão, começa-se pela ignorância que se tem do problema, e não por aquilo que se conhece. A zona de ignorância éo meio, a zona de imersão ambiente, como no caso do peixe dentro d'água: a água é aquilo que ele desconhece completamente.
Os simbolistas já haviam descoberto isso.

Eles diziam que, para escrever um poema, é preciso começar sabendo o efeito que se quer produzir, o que determinará aquilo que será colocado dentro. Foi Edgar Allan Poe que ensinou essa técnica a Baudelaire, em seu estudo sobre os princípios da poesia. Mallarmé, como se sabe, dirigia uma revista de moda. Escritores como Flaubert estudavam todas as modas, mesmo as mais banais. O que quero dizer, simplesmente, é que não estudo o que o peixe faz, mas o seu meio, seu ambiente.

\section{L'Express: Porque de fora sempre temos} uma visão melhor.

M. McLuhan: Porque o ambiente é sempre invisível. O idioma francês, por exemplo, éo meio em que vocês se banham e sobre o qual não conhecem muita coisa, exatamente por estarem imersos dentro dele. Um inglês sabe muito mais sobre a língua francesa do que vocês mesmos, porque ele se surpreende com suas expressões. Para o inglês, tudo isso é playback, "replay", enquanto para vocês é "play".

\section{L'Express: Sua grande descoberta foi ter} mostrado que o meio constitui um ambiente. Qual é a sua definição de meio de comunicação? M. McLuhan: Tudo que amplia a ação do agente humano. As roupas, por exemplo, são extensões, ampliações. A linguagem é um prolongamento, uma ação a distância que compreende uma memória, um sistema de codificação. Ela 
assimila as percepções, conduzindo-as e canalizando-as. Todas as formas de expressão são meios de comunicação, e descobri recentemente que o conteúdo do meio é antes de tudo seu usuário. Aquele que fala francês éo conteúdo da língua francesa, aquele que assiste televisão é o conteúdo da televisão, etc.

L'Express: Sua ideia parece fascinante, mas não é ao mesmo tempo muito paradoxal?

M. McLuhan: Um psicólogo da General Electric em Nova York, Herbert Krubmann, também não acreditava nas minhas ideias e decidiu utilizar o encefalograma para ver se o conteúdo de diferentes meios importava ou não. Ele usou seus pacientes nessa experiência, submetendo-os a diversos meios, e constatou que a reação das ondas cerebrais ao texto impresso, ao cinema, $\grave{a}$ fotografia, ao radio e à televisão fazia com que aparecessem variações muito relevantes.

Por outro lado, pouco importava o que havia no meio. Pouco importava se o rádio era barulhento ou não - o cérebro não respondia às variações de programas. As respostas variavam apenas em função do meio utilizado. Krubmann achou que conseguiria reduzir a pó as teorias de McLuhan.

Para isso, ele gastou muito dinheiro, e o resultado foi que conseguiu estabelecer a primeira prova de que essas teorias são cem por cento corretas.

Entretanto, quando afirmo que o meio, o meio de difusão, é a mensagem, isso diz respeito ao efeito desse meio na sociedade como um todo, à maneira como ele transforma todo mundo. Isso é a mensagem, e não seus efeitos particulares.

\section{L'Express: E qual seria, mais especificamente, o} efeito da televisão sobre a nossa sociedade?

M. McLuhan: Por meio da linguagem, da fala, nós traduzimos nossas percepções do mundo visível em sons, em formas verbais. Com a televisão, ao contrário, as formas verbais desaparecem, dando lugar a "gestos" bastante simples e universais. A partir do advento da televisão, a juventude tornou-se cada vez mais verbal. Os jovens dizem: "Na verdade... é... cara... eu queria dizer, cara... quer dizer..." A geração da TVnão utiliza mais do que uma dezena de palavras. Este é um dos inúmeros efeitos provocados pela televisão.

\section{L'Express: Claro, mas isso não é exatamente consequência do que a televisão lhes mostra?} M. McLuhan: Não, de modo algum. Se você passa um filme na televisão, não importa qual seja, ele é veiculado por ela, é conduzido por ela. No cinema, você olha para a tela, com a televisão vocêé a tela, pois a luz lhe chega através do tubo catódico. O cinema é visual, ao passo que a TV é áudio-tátil. É possível compará-la ao efeito de um vitral. Não é a imagem representada pelo vitral que chama atenção, mas a luz que passa através dele. Ou como a pintura de Soulages, em que a luz nos arrebata.

De forma mais ampla, é todo nosso ambiente elétrico que é responsável por nossa transformação. Se mergulhamos na água e começamos a nadar, não temos mais nenhum ponto de vista, estamos dentro de um meio envolvente total. Com o ambiente elétrico, 
também deixamos de ter ponto de vista e objetivo.

Porque sempre já alcançamos o lugar aonde queremos ir, seja qualfor.

Tudo começou com o telégrafo. O primeiro homem que foi conectado à linha de frente por meio do telégrafo foi Abraham Lincoln, em 1860. Ele era presidente dos Estados Unidos e chefe das Forças Armadas. 0 resultado de sua ligação telegráfica com o front, do ponto de vista da capacidade de tomada de decisão, foi revolucionário, pois o chefe de Estado também se engajava na ação de combate. Ele não estava mais afastado da ação, mas participava dela, encontrava-se dentro dela. Hoje em dia, você pega o telefone e está em Tóquio. Eles estão aqui e você, lá. Não de trata de um desejo, mas de um fato. E é sagrado, desencarnado. $O$ espírito parte na mesma hora para Tóquio. Não existe mais corpo, hardware. Existe apenas software.

\section{L'Express: E como isso explica a perda de vocabulário observada nos jovens?}

M. McLuhan: É uma questão de espaço. $O$ racionalista tal como o Ocidente o compreende há milênios é um classificador: ele ordena, organiza, extrai perspectivas, traça largas avenidas. Com o espaço elétrico, ao contrário, são os intervalos entre as coisas que se tornam decisivos.

O espaço elétrico é absoluto. É como o espaço acústico, aberto a 360 graus, ressonante. Não se consegue mais localizar nele coisas e conceitos. $E ́$ como a roda e o eixo. Para que a roda gire, é preciso que um pequeno espaço os separe, não muito grande, senão a roda cai e para de girar também.
Isso é o que acontece com a geração da TV. Os garotos, atualmente, são todos caçadores. Eles deixaram o neolítico e regressaram ao paleolítico. É por isso que querem andar descalços sobre a terra, por isso que aspiram a uma vida primitiva e não querem ter mais nada em comum com o mundo do consumo. E esse tipo de homem é o esquimó, é Brancusi, Bergson, é o homem não visual, que escuta, percebe e ouve tudo com os dedos. Muito mais do que nós, o caçador se serve de suas percepções, pois ele deve ser capaz de ler a fundo o ambiente em que está inserido.

\section{L'Express: Não seria o caso de dizer que} os jovens "botam para fora" precisamente o mundo da TV que os oprime e que eles não podem mais aguentar?

M. McLuhan: Eles reagem, claro. $O$ rock e o jazz, por exemplo, não passam de uma tradução para a linguagem musical de sons repugnantes e irracionais do ambiente industrial. Uma forma de humanizá-lo. Eles tentam traduzir o ruído industrial em uma linguagem que conheçam para poder coabitar com ele.

No entanto, o mais importante é que eles regressam a uma existência primitiva, na qual a vida é reduzida a nada, e não possuem mais nenhuma espécie de identidade. Eles rejeitam a própria identidade. Tornam-se ninguém. Eu disse agora há pouco que a roupa era um meio. Vejamos o exemplo da minissaia. 
Antes da minissaia havia um artefato que a gente chamava de bambolê, lembra? Era um aro de plástico que as pessoas faziam girar em volta da cintura. Elas não brincavam de rodar o aro na rua como as crianças fazem, não, ninguém nunca fez isso com um bambolê. Ora, fazer rodar um aro equivale a usá-lo como se fosse uma máquina, uma roda, ao passo que colocar-se dentro dele e fazê-lo girar significa utilizá-lo como roupa.

Traduzir a roda em roupa é uma ideia bastante misteriosa. Mas o bambolê veio antes da minissaia, que é uma espécie de roda. E a minissaia é usada por todas as tribos, homens e mulheres.

\section{L'Express: Mas trata-se de uma roupa? A} minissaia não seria, antes, um traje?

M. McLuhan: Claro, com certeza. Nos Estados Unidos, um policial, por exemplo, com sua roupa de burocrata, é um "pig", um funcionário perfeito para aplicar a norma e anotar as multas. Em seu traje de motociclista, ao contrário, ele se torna um herói. E, de óculos, até mesmo um ciclope, um herói de um olho só.

Mas o traje é nosso costume. Não dá para criar sozinho um costume, é preciso um monte de gente para isso. Portanto, a minissaia é um traje e uma máscara. As pessoas a usam, de alguma maneira, para canalizar, codificar a energia social e entrar assim no espetáculo. Ela é uma máscara coletiva. No mundo ocidental, fazia séculos que não tínhamos uma máscara assim.

\section{L'Express: É a sua teoria da aldeia global, da} humanidade inteira formando nada mais do que uma imensa tribo planetária.

M. McLuhan: Sim, e isso é a eletricidade, é a televisão. E todos nós somos afetados, não apenas os jovens.

Eis o seu último dia com você mesmo. Você não precisa mais ser você mesmo. É uma libertação, mas quando essa libertação é total, ela é como a morte. Todos conhecem a tese da reencarnação: somos libertados de nosso próprio corpo, podemos desaparecer agora mesmo e voltar, sendo completamente diferentes da próxima vez. É onde chegamos.

A maioria das pessoas têm cachorro apenas para se lembrar quem são. É por isso que os cachorros são tão importantes na nossa sociedade. Eu sei quem eu sou porque o meu cãozinho me conhece. Ele éo guardião do meu segredo, conhece meu cheiro, é ele que garante a minha identidade. No mundo atual, é o cachorro que tem o controle de tudo.

\section{L'Express: 0 que o senhor chama de perda de} identidade não representa, por outro lado, 0 surgimento de uma certa solidariedade?

M. McLuhan: O que se assume como base quando se fala em solidariedade? A base só pode ser a civilização. Ora, é evidente que nós nos saímos bem, pois ela está fundada sobre diversas tecnologias especializadas, como o texto escrito, o alfabeto, a fonética, e não vejo como podemos fazê-la resistir à eletricidade, que não é especializada. O que temos agora é a multidão, a meio caminho entre a civilização antiga e a tribo 
nova. E a multidão é apenas confusão.

Sabe como os americanos chamam isso? De, literalmente, "caixa de minhocas". É uma expressão usada para quando existem inúmeros problemas, entrelaçados uns nos outros. É isso que temos agora, uma espécie de caixa de Pandora.

L'Express: 0 senhor é incrivelmente pessimista, o que é algo bastante inesperado para 0 apóstolo dos meios de comunicação.

M. McLuhan: Não sou nem pessimista nem otimista. Não faço julgamentos de valor. Tenho apenas um interesse profundo em compreender o que acontece, ao mesmo tempo em que não me animo muito diante dos fatos.

No momento em que estamos, é possível ter uma consciência completamente imbricada. É a época mais metafísica que já existiu no sistema da humanidade. Mas não se trata de metafísica teórica-o homem deixou de ser conceitual. Sua metafísica passou a ser perceptiva.

Quero dizer que ele sai do mundo da lógica para entrar no mundo da mística, com percepções imediatas. De tal modo que não é mais necessário ensinar filosofia a ninguém. Agora as pessoas trazem a filosofia no sangue. $\mathrm{Na}$ minha opinião, estamos vivendo a época mais metafísica de toda a História.

L'Express: É aí que o senhor vê surgir o fosso entre as gerações?

M. McLuhan: Sim, entre essa equipe antiquada que carrega o hardware do século XIX, composta de indivíduos ultraespecializados e vidrados por produtos de consumo, e as novas aspirações da juventude. Deslizamos do grupo de especialistas mais fragmentado que já existiu para o seu oposto. E veja o que acontece: ao deslizarmos, ao nos livrarmos do hardware, o que regressa é o ocultismo. Expliquei em um dos meus livros que quando uma inovação irrompe, sempre descartamos o ambiente imediato para procurar por um muito mais antigo. Quando Gutenberg aniquilou a Idade Média ao inventar a imprensa, trouxe de volta a Antiguidade pagã, greco-romana. Houve então uma grande corrida, mas ele havia destruído a Idade Média. Hoje, que nós já detonamos a quinquilharia do século XIX com o surgimento da eletricidade, fizemos vir à tona toda a vida interior. E vivemos atualmente uma viagem eterna rumo à vida interior.

\section{L'Express: 0 senhor quer dizer que nós assistimos a um renascimento da atitude religiosa?}

M. McLuhan: Não. Eu diria na verdade que o que está acontecendo vai além da religião e não depende de fé alguma nem de qualquer outra coisa. É uma experiência total e imediata. Hoje em dia, os jovens são todos religiosos sem, no entanto, terfé.

\section{L'Express: Eles têm uma religião,} mas não um Deus.

M. McLuhan: Eles até podem ter um Deus se 
quiserem, mas não há essa necessidade. Afrase de Nietzsche é conhecida: "Deus está morto." Eu acredito mais que Newton é que está morto, porque junto com ele desapareceu o grande mundo racionalista da dinâmica e da matemática. Simples assim. Ele sumiu da mesma forma como evaporou o hardware industrial.

\section{L'Express: Claro, mas Deus veio}

antes de Newton.

M. McLuhan: De fato, e eu, pessoalmente, sou um católico convicto. No entanto, constato que o que acontece com o mundo hoje em dia não tem nada a ver com isso, pois não é necessário que nosso mundo seja religioso no sentido cristão do termo para ser totalmente espiritualizado.

Sempre penso que Lúcifer, o príncipe deste mundo, era um grande engenheiro elétrico, $o$ chefe de todo esse universo diabólico, o senhor de tudo! Lúcifer era um anjo de prodigiosa inteligência, e parece ter sido ele quem organizou a situação na qual vivemos atualmente. E o que é angelical poderia muito bem ser diabólico.

Mas não sei. Quem sabe? De todo modo, é ele que conduz o jogo.

James Joyce, em Finnegans Wake, conta 10 trovões. Eles vão desde a fala até a televisão. A televisão é o trovão no 10 , depois de passarem as revoluções agrícolas, industriais e o rádio. Quando se chega à televisão é o fim. Não se pode seguir adiante, estamos totalmente abarcados pelo processo mundial. Mas é estranho, porque os trovões de Joyce representam os efeitos da visão interior, o rumor que ecoa enquanto os efeitos se propagam entre os homens, de tal forma que cada inovação reverbera por toda a sociedade.

\section{L'Express: Isso quer dizer que estamos ao} mesmo tempo diante de uma necessidade metafísica imperiosa e de um vazio espiritual? M. McLuhan: Quando falamos em vazio, estamos implicitamente falando de um recipiente, e um recipiente é algo bastante visual, bem hardware. Na cultura chinesa, ao contrário, o grande mistério é o vazio. Não a parte externa do vaso, mas seu interior. No Ocidente temos apenas uma epistemologia do conhecimento, só sistematizamos aquilo que acreditamos conhecer. Já o oriental busca descobrir o que não conhece.

Os jovens estão doentes, sem dúvida. Vou dar um exemplo. A filha de uns amigos nossos recebeu o primeiro beijo há pouco tempo. Como ela sabia que isso era iminente, perguntou a uma amiguinha o que precisava fazer. A amiguinha respondeu: "Você cospe na boca dele, e ele cospe na sua." É assim que os jovens enxergam as coisas. É insano.

Por outro lado, alguns estão adquirindo esse hábito oriental de começar pela ignorância e não mais pelo conhecido. No romance policial acontece o mesmo: o detetive começa por aquilo que não conhece.

L'Express: Entretanto, ainda continua existindo em nossa sociedade uma boa quantidade de hardware. Como o automóvel, por exemplo, cuja tecnologia remonta ao século XIX.

M. McLuhan: O carro, sem dúvida, é algo totalmente antiquado. Seu futuro talvez será 
sobre a Lua, mas dentro de 10 anos os carros serão proibidos nas cidades, é inevitável. Faz pouco tempo que descobrimos isto em Toronto. Eu me perguntava por que os americanos não permitem que haja publicidade no cinema ou no teatro se na televisão eles autorizam. É um fenômeno bastante curioso: um americano que visse algum tipo de publicidade na tela do cinema levantaria imediatamente para pedir o seu dinheiro de volta.

Não fui eu que encontrei a resposta, mas um dos meus estudantes do doutorado, que fez a seguinte observação: "Pois é, nós, americanos, saímos de casa para ter privacidade!" Os europeus voltam para casa com o intuito de encontrar lá sua vida privada e saem para estar em comunidade. Para os americanos, é o contrário. Eles saem para ter privacidade e passam a estar em comunidade assim que entram em casa. Realmente, nos lares americanos as portas estão sempre abertas, a criançada manda em tudo, especialmente no pai, que não passa de uma bela farsa. 0 resultado é que o carro é o elemento particular mais privilegiado da vida americana.

Quando um americano sente a necessidade de se sentir sozinho, ele sai de carro. É por isso que não utiliza os meios de transporte públicos, o que é um enorme problema.

\section{L'Express: E na Europa? Será que isso não é} assim nos Estados Unidos porque os meios de comunicação lá são mais abundantes do que aqui? Porque o país tem uma tecnologia mais avançada? M. McLuhan: Não, isso data da época em que os descobridores nutriam o sentimento de possuir o mundo inteiro. O lado de fora é que era o espaço privado. Como Robinson Crusoé. Na América do Norte, as pessoas têm a sensação de serem donas do mundo quando saem, e não quando estão entre quatro paredes. Não é o que acontece na Europa.

\section{L'Express: Por quê?}

M. McLuhan: Porque a Europa é muito menor.

\section{L'Express: Em sua descrição dos efeitos} dos meios de comunicação sobre o mundo moderno, o senhor não subestima um pouco a atitude conservadora?

M. McLuhan: Não sei, não tenho certeza, pois é difícil separar o que permanece daquilo que se transforma ao longo do percurso.

Isso acontece quando passamos a utilizar a linguagem de uma nova forma. Se de uma hora para outra, no restaurante, eu peço a "monta" em vez de pedir a "conta", há uma inversão de linguagem. Quando introduzimos novos patterns na língua, o que acontece com a antiga? É difícil saber.

Fazemos isso o tempo todo. Transformamos a língua sem parar, em função de novas percepções. O slang - a gíria - é, na verdade, uma zona de novas percepções. Quando uma nova percepção surge, as pessoas sentem a necessidade de criar uma expressão nova, $e$ então inventam uma.

Depois de quatro ou cinco anos nos Estados Unidos, uma coisa impressionante é que nós utilizamos a cada 30 segundos a expressão where 
it is at, que pode ser traduzida por "onde isso se passa”. É um grande salto, uma grande incursão no domínio da consciência metafísica, por causa da palavra "isso", que é nova na América. Nos anos 1920, a expressão de gíria que se utilizava era: I'll tell the world (Eu vou dizer ao mundo). Por exemplo, I'll tell the cock-eyed world (Eu vou dizer a esse mundo de doidos). Estávamos na era do rádio, ao passo que a era da televisão apresenta uma expressão muito tranquila, profunda: Where it is at. O "eu" se apaga diante do "isso" impessoal, neutro. É o mais metafísico possível. E nos Estados Unidos os jovens o utilizam a cada minuto. Tratase do sinal de uma grande mudança de percepção. A palavra slang significava, na origem, vestido, ou seja, tinha relação com a roupa. E, naturalmente, a linguagem é uma roupa. Mas o slang é um novo traje usado momentaneamente para criar um efeito.

\section{L'Express: E os livros, os jornais, não são} um traje antigo? Sua existência não indica, até os dias de hoje, uma certa sobrevivência da galáxia de Gutenberg?

M. McLuhan: Ah, estamos longe de ter acabado com a imprensa! A impressão terá inúmeras aplicações novas. As antigas aplicações vão sumindo e surgem outras a cada instante. A impressão da voz é algo realmente espantoso, não? Assim como a impressão direta das ondas cerebrais, graças ao encefalograma. Nossos jornais são elétricos, no sentido de que sãofeitos a partir de agências de notícias que prometem uma cobertura instantânea dos fatos.
Observe qualquer página e poderá ver que se trata de colagem. Isso é tão claro que ninguém lê uma parte do jornal tentando compreender uma outra parte. O leitor nunca procura conexões entre as diversas partes. Mas tudo ressoa, faz eco. Um jornal vibra, interfere, é uma imagem induzida do mundo sobre uma superfície plana e em forma de mosaico, cuja única unidade é a data em comum. A primeira página dos jornais quase sempre é reservada às notícias ruins, geralmente é pesada e triste. Sabe por quê? Por causa da publicidade, que, por meio de todos os serviços que propõe, consiste sempre em um conjunto de notícias agradáveis. $E$ quando se deseja vender essas notícias agradáveis, é preciso que haja igualmente notícias ruins. Isso é um fato, sem cinismo. É verdade. As pessoas não vão ler notícias agradáveis se não forem apresentadas também a notícias ruins. Uma das razões para isso é que, quando elas tomam conhecimento de episódios tristes, experimentam o sentimento do sobrevivente: "Dessa eu me safei, continuo firme e forte", etc. De talforma que, quanto mais leem noticias ruins, melhor se sentem.

\section{L'Express: Infelizmente, esse sentimento} não é eterno? Está ligado apenas aos meios de comunicação?

M. McLuhan: Os meios de comunicação o ampliam. Fabricar notícias se tornou algo muito maior do que as próprias notícias, visto que as equipes que trabalham nas agências são enormes, da mesma forma como são poderosos os meios de difusão. O que é novo é ter essa 
quantidade de informação ao mesmo tempo. Isso transforma qualquer tentativa classificatória em ilusão. Hoje em dia, a inteligibilidade não passa de um "pattern-recognition", uma tentativa de trazer à tona os esquemas.

Tudo isso cria uma outra galáxia, de contornos novos. E tudo apresenta esse paradoxo, pois aqui é a velocidade que está em jogo.

\section{L'Express: E o que podem fazer as pessoas que} controlam os meios de comunicação?

M. McLuhan: Nada, porque na verdade elas não os controlam. E nem saberiam como fazer isso. Diante do nível de velocidade a que chegamos, o dirigente no topo da pirâmide não pode mais tomar decisões. Ele está fora da jogada. As decisões são tomadas em um nível muito mais baixo do organograma. Seja qual for a organização em questão, o dirigente é apenas um ornamento. É como o problema de apertar um botão. O exemplo da bomba atômica é célebre: 0 presidente dos Estados Unidos nunca pode ficar a uma distância maior do que 20 minutos dos comandos e das informações que precisa ter para apertar o botão. De tal modo que, se ele vai à China, é preciso que deem um jeito de ele estar a 20 minutos de tudo que precisa dispor para apertar o botão, caso seja necessário.

Trata-se de uma forma bastante incômoda de viajar.

L'Express: Mas é exatamente ele que toma a decisão. Isso não contradiz a sua ideia de que são os meios que comandam?
M. McLuhan: Não, pois ele precisa de milhares de pessoas para lhe dizer quando deve apertar o botão. É estranho que quanto mais rápidas e consistentes são as notícias, mais descentralizada é a decisão. O que acontece no plano elétrico é um efeito centrífugo em direção à periferia.Atualmente isso se verifica em todos os países do mundo, na Irlanda do Norte, na França, na Grã-Bretanha. As regiões não querem mais ficar sob a influência da grande organização central. Assim, dentro de um carro nos sentimos bem mais independentes do que em um trem. Os trens precisam permanecer sobre os trilhos, passar pelas estações, pelos nós ferroviários, para deixar os passageiros desembarcarem. Com o carro, isso não é mais necessário. Nem mesmo é preciso pertencer a uma metrópole.

\section{L'Express: Como o senhor enxerga o amanhã?} M. McLuhan: O futuro já é agora, não existe amanhã. Tudo o que pode acontecer nos próximos 100 anos, já aconteceu. Não somos capazes de mencionar nada que tenha sucedido no passado que já não estivesse presente 100 anos antes. Na verdade, todo elemento de novidade sempre está presente 100 anos antes de seu advento, seja na ciência, seja em outras áreas.

Creio que nos limitando a descrever o presente já estamos sendo apocalípticos.

L'Express: 0 senhor dá a impressão de falar como um homem de antigamente. 
M. McLuhan: Como estudioso dos meios de comunicação, meu papel é somente o de organizar a percepção. Mas é claro que há um limite naquilo que podemos aceitar. Ninguém gostaria de ficar dentro de um avião o tempo todo. Quando se transgride a dimensão humana, a tendência é que a reação venha em forma de elementos infinitamente menores, simples. É por isso que os jovens se voltam para as pequenas coisas.

L'Express: E, como eles, o senhor também deseja viver na dimensão humana.

\section{McLuhan: Claro, só que não leva a nada} ficar apenas sonhando com isso, pois não é algo fácil de realizar.

Há muitos jovens que assim desejam, e provavelmente chegarão lá. O que vão fazer é deixar esse mundo, largá-lo exatamente no estágio em que se encontra. Não vão tentar melhorá-lo, mas vão simplesmente abandonálo, deixar apodrecer.

Já é o que está ocorrendo. Em Saint Louis e outras cidades dos Estados Unidos, as pessoas começaram a deixar os centros urbanos. Abandonam os móveis nos apartamentos, largam tudo e simplesmente vão embora, para não voltar nunca mais. É como se deixassem para trás uma cidade condenada. Em Saint Louis mesmo, há muitos quilômetros quadrados de apartamentos vazios, que os moradores acabaram de abandonar. Continuam sendo os proprietários ou locatários, mas não voltarão mais.

\section{L'Express: Quer dizer que o que parece ser} o amanhã é na verdade uma certa nostalgia do passado?

M. McLuhan: Acho que somos conduzidos atualmente a fazer uma crítica das recompensas. De todas as nossas técnicas, invenções, conhecimentos, etc., o que ganhamos? E quando as pessoas têm certeza de que não estão ganhando absolutamente nada, simplesmente abrem mão.

É como um homem rico, muito rico, que ganha hoje 100.000 dólares por ano. A maioria dos serviços que os ricos podem adquirir são gratuitos para os muito pobres. A grosso modo, o pobre dispõe dos mesmos serviços que o rico. Portanto, quais podem ser as vantagens da riqueza?

Alguns dos homens mais ricos do momento, como Howard Hughes, devem milhares de dólares e não têm um tostão. Mas eles devem tanto dinheiro que seus credores gastam uma fortuna para que eles permaneçam muito ricos. É o que acontece no mundo em que vivemos. Temos muitas recompensas, as mais variadas e abrangentes. Aí também a dimensão humana desaparece.

\section{L'Express: Ao ouvi-lo, temos a impressão} de que uma de suas principais defesas é o senso de humor.

M. McLuhan: Não sei. Quando faço uma descoberta - algo que poderíamos ter compreendido muito tempo antes -, começo a rir. Por um lado, de surpresa, por outro, de 
satisfação, ou ainda de repulsa. Mas também uma grande parte do meu trabalho consiste em uma sátira baseada essencialmente na observação do que está se passando. Porque a maior sátira que pode haver, para mim, parece ser simplesmente registrar o que vem ocorrendo. Erasmo, como todos sabem, escreveu o Elogio da loucura, acreditando que quando se faz o elogio das tolices, elas explodem e somem. Acredito que se possuo esse tipo de humor e se consigo atrair a atenção para o absurdo do nosso mundo, talvez ele possa desaparecer, explodir.

Por outro lado, não me parece ter muita importância o que sou capaz de pensar ou sentir a respeito de seja lá o que for, porque não acho que isso possa dar em alguma coisa. Não tenho nenhuma ilusão quanto à influência que exerço ou que posso ter exercido. Me identifico mais com o coro das tragédias antigas, que existe apenas para comentar a ação, e não para modificá-la. Nós vivenciamos uma enorme evolução regressiva das formas culturais, que começou com os românticos, quando eles começaram a adorar o bom selvagem e a demonstrar sentimento pelos primitivos, como Rousseau e Cia. Depois, veio a eletricidade e junto com ela a paixão do mundo inteiro pela antropologia, que é o estudo dos primitivos. Hoje, a eletricidade é a atualidade dos primitivos.

\section{L'Express: E quanto ao pensamento} revolucionário? Ele não pode trazer uma solução aos problemas do mundo atual? M. McLuhan: As pessoas de esquerda, pelo que pude perceber até hoje, avaliam tudo em termos de hardware, ou seja, pertencem ao século XIX. Elas se baseiam em categorias muito simplistas de consumidores. Acreditam que se todos os homens tivessem a mesma quantidade de alimento e as mesmas condições de vida tudo se resolveria e passaria a haver paz no mundo. Afinal de contas, Marx é um homem do século XIX. Não é um homem da era elétrica. De modo que eu me preocupo pouco com as pessoas de esquerda, exceto pelo fato de que elas retêm muito a atenção, impedindo-a de se dirigir para "onde as coisas se passam".

Além disso, acho que elas utilizam Marx como meio de indignação. Sabemos que a raiva se tornou para muitos um modo de vida. A maioria dos indivíduos sentem-se realizados quando estão com raiva. Têm a sensação de estarem integrados.

O que a China e Rússia desejam é o século XIX. Os chineses e os russos não querem o século XX. E tampouco a África: ela busca o século XIX.

L'Express: 0 senhor acaba de terminar um livro, Take today - the executive as dropout, dedicado ao mundo industrial. Do que ele trata?

M. McLuhan: Da transformação dos mecanismos decisórios no mundo inteiro, em diferentes culturas. Esse livro teve início há muito tempo, quando comecei a me dar conta de que as equipes gerenciais eram mais receptivas a novas ideias do que qualquer outro grupo. Como os gestores se interessam pela própria sobrevivência, querem estar a par do que acontece. Já os teóricos das 
universidades, ao contrário, se interessam por prestígio e são, por esse motivo, muito hostis às inovações, às ideias novas.

\section{L'Express: Então é um livro sobre g} estão empresarial?

M. McLuhan: Não exatamente. O coautor, Barrington Nevitt, é engenheiro elétrico e consultor de empresas. Ele passou muitos anos na Escandinávia, na Rússia, na América do Sul, na Grã-Bretanha, nos Estados Unidos. Tem uma vasta experiência em diferentes burocracias e fala 12 línguas. De forma que não há problema que tenha surgido no mundo industrial que não o tenha interessado, direta ou indiretamente.

\section{L'Express: Existe algum conselho que o}

\section{Senhor possa dar, no plano político, para} melhorar a situação atual?

M. McLuhan: Claro. Por exemplo, se quisessem melhorar a situação no Oriente Próximo, seria preciso fazer calar o rádio e substituí-lo pela televisão. E imediatamente. Veja bem, Hitler não se sustentaria mais do que o tempo de uma aparição na TV, porque na TV não é possível cerrar os punhos e bradar. É preciso que seja "frio", calmo. Hitler seria visto uma vez e depois estaria acabado.
0 rádio é um meio "quente". Ele produz Hitlers a torto e a direito e deixa a sociedade como um todo em estado de ebulição. É uma loucura permitir o rádio em países subdesenvolvidos: na China, no mundo muçulmano, na Índia. É como pôr lenha na fogueira. 


\section{Expediente}

A revista E-Compós é a publicação científica em formato eletrônico da Associação Nacional dos Programas de Pós-Graduação em Comunicação (Compós). Lançada em 2004, tem como principal finalidade difundir a produção acadêmica de pesquisadores da área de Comunicação, inseridos em instituições do Brasil e do exterior.
E-COMPÓS I www.e-compos.org.br I E-ISSN 1808-2599

Revista da Associação Nacional dos Programas

de Pós-Graduação em Comunicação.

Brasília, v.14, n.3, set./dez. 2011.

A identificação das edições, a partir de 2008

passa a ser volume anual com três números.
CONSELHO EDITORIAL

Afonso Albuquerque, Universidade Federal Fluminense, Brasil Alberto Carlos Augusto Klein, Universidade Estadual de Londrina, Brasil Alex Fernando Teixeira Primo, Universidade Federal do Rio Grande do Sul, Brasil Ana Carolina Damboriarena Escosteguy, Pontifícia Universidade Católica do Rio Grande do Sul, Brasil

Ana Gruszynski, Universidade Federal do Rio Grande do Sul, Brasil Ana Silvia Lopes Davi Médola, Universidade Estadual Paulista, Brasil André Luiz Martins Lemos, Universidade Federal da Bahia, Brasil Ângela Freire Prysthon, Universidade Federal de Pernambuco, Brasil Angela Cristina Salgueiro Marques, Faculdade Cásper Líbero (São Paulo), Brasil Antônio Fausto Neto, Universidade do Vale do Rio dos Sinos, Brasil Antonio Carlos Hohlfeldt, Pontifícia Universidade Católica do Rio Grande do Sul, Brasil Antonio Roberto Chiachiri Filho, Faculdade Cásper Líbero, Brasil Arlindo Ribeiro Machado, Universidade de São Paulo, Brasil

Arthur Autran Franco de Sá Neto, Universidade Federal de São Carlos, Brasil Benjamim Picado, Universidade Federal Fluminense, Brasil César Geraldo Guimarães, Universidade Federal de Minas Gerais, Brasil Cristiane Freitas Gutfreind, Pontifícia Universidade Católica do Rio Grande do Sul, Brasil Denilson Lopes, Universidade Federal do Rio de Janeiro, Brasil Denize Correa Araujo, Universidade Tuiuti do Paraná, Brasil

Edilson Cazeloto, Universidade Paulista , Brasil

Eduardo Peñuela Cañizal, Universidade Paulista, Brasil Eduardo Vicente, Universidade de São Paulo, Brasil Eneus Trindade, Universidade de São Paulo, Brasil Erick Felinto de Oliveira, Universidade do Estado do Rio de Janeiro, Brasil Florence Dravet, Universidade Católica de Brasília, Brasil Francisco Eduardo Menezes Martins, Universidade Tuiuti do Paraná, Brasi Gelson Santana, Universidade Anhembi/Morumbi, Brasil Gilson Vieira Monteiro, Universidade Federal do Amazonas, Brasil Gislene da Silva, Universidade Federal de Santa Catarina, Brasil Guillermo Orozco Gómez, Universidad de Guadalajara Gustavo Daudt Fischer, Universidade do Vale do Rio dos Sinos, Brasil Hector Ospina, Universidad de Manizales, Colômbia Herom Vargas, Universidade Municipal de São Caetano do Sul, Brasil leda Tucherman, Universidade Federal do Rio de Janeiro, Brasi Inês Vitorino, Universidade Federal do Ceará, Brasil Janice Caiafa, Universidade Federal do Rio de Janeiro, Brasi Jay David Bolter, Georgia Institute of Technology Jeder Silveira Janotti Junior, Universidade Federal de Pernambuco, Brasil João Freire Filho, Universidade Federal do Rio de Janeiro, Brasi John DH Downing, University of Texas at Austin, Estados Unido José Afonso da Silva Junior, Universidade Federal de Pernambuco, Brasil
José Carlos Rodrigues, Pontifícia Universidade Católica do Rio de Janeiro, Brasil José Luiz Aidar Prado, Pontifícia Universidade Católica de São Paulo, Brasil José Luiz Warren Jardim Gomes Braga, Universidade do Vale do Rio dos Sinos, Brasi Juremir Machado da Silva, Pontifícia Universidade Católica do Rio Grande do Sul, Brasil Laan Mendes Barros, Universidade Metodista de São Paulo, Brasil Lance Strate, Fordham University, USA, Estados Unidos Lorraine Leu, University of Bristol, Grã-Bretanha Lucia Leão, Pontifícia Universidade Católica de São Paulo, Brasil Luciana Panke, Universidade Federal do Paraná, Brasil Luiz Claudio Martino, Universidade de Brasília, Brasil Malena Segura Contrera, Universidade Paulista, Brasi Márcio de Vasconcellos Serelle, Pontifícia Universidade Católica de Minas Gerais, Brasil Maria Aparecida Baccega, Universidade de São Paulo e Escola Superior de Propaganda e Marketing, Brasil

Maria das Graças Pinto Coelho, Universidade Federal do Rio Grande do Norte, Brasil Maria Immacolata Vassallo de Lopes, Universidade de São Paulo, Brasil Maria Luiza Martins de Mendonça, Universidade Federal de Goiás, Brasi Mauro de Souza Ventura, Universidade Estadual Paulista, Brasil Mauro Pereira Porto, Tulane University, Estados Unidos

Nilda Aparecida Jacks, Universidade Federal do Rio Grande do Sul, Brasil Paulo Roberto Gibaldi Vaz, Universidade Federal do Rio de Janeiro, Brasil Potiguara Mendes Silveira Jr, Universidade Federal de Juiz de Fora, Brasil Renato Cordeiro Gomes, Pontifícia Universidade Católica do Rio de Janeiro, Brasil Robert K Logan, University of Toronto, Canadá Ronaldo George Helal, Universidade do Estado do Rio de Janeiro, Brasil Rosana de Lima Soares, Universidade de São Paulo, Brasil Rose Melo Rocha, Escola Superior de Propaganda e Marketing, Brasil Rossana Reguillo, Instituto de Estudos Superiores do Ocidente, Mexico Rousiley Celi Moreira Maia, Universidade Federal de Minas Gerais, Brasil Sebastião Carlos de Morais Squirra, Universidade Metodista de São Paulo, Brasil Sebastião Guilherme Albano da Costa, Universidade Federal do Rio Grande do Norte, Brasil

Simone Maria Andrade Pereira de Sá, Universidade Federal Fluminense, Brasi Tiago Quiroga Fausto Neto, Universidade de Brasília, Brasil Suzete Venturelli, Universidade de Brasília, Brasil Valério Cruz Brittos, Universidade do Vale do Rio dos Sinos, Brasil Valerio Fuenzalida Fernández, Puc-Chile, Chile

Veneza Mayora Ronsini, Universidade Federal de Santa Maria, Brasil Vera Regina Veiga França, Universidade Federal de Minas Gerais, Brasil Valerio Fuenzalida Fernández, Puc-Chile, Chile Veneza Mayora Ronsini, Universidade Federal de Santa Maria, Brasil Vera Regina Veiga França, Universidade Federal de Minas Gerais, Brasil

\section{COMISSÃO EDITORIAL}

Adriana Braga I Pontifícia Universidade Católica do Rio de Janeiro, Brasil Felipe Costa Trotta I Universidade Federal de Pernambuco, Brasil

CONSULTORES AD HOC

Édison Gastaldo, Universidade Federal Rural do Rio de Janeiro, Brasil

EDIÇÃO DE TEXTO E RESUMOS I Susane Barros

SECRETÁRIA EXECUTIVA I Juliana Depiné

EDITORAÇão ELETRÔNICA I Roka Estúdio

TRADUÇÃO I Sieni Campos e Robert Finnegan
COMPós I www.compos.org.br

Associação Nacional dos Programas de Pós-Graduação em Comunicação

Presidente

Julio Pinto

Pontifícia Universidade Católica de Minas Gerais, Brasi

juliopinto@pucminas.br

Vice-presidente

Itania Maria Mota Gomes

Universidade Federal da Bahia, Brasil

itania@ufba.br

Secretária-Geral

Inês Vitorino

Universidade Federal do Ceará, Brasil

inesvict@gmail.com 